\title{
PREVENDO O COMPORTAMENTO DE CURTO-PRAZO DA TAXA DE JUROS SELIC A PARTIR DE UM MODELO VAR COM RESTRIÇÃO
}

\author{
Luciano D'Agostini ${ }^{11}$ \\ José Luís da Costa Oreiro ${ }^{12}$
}

Um aspecto sobre o desempenho futuro da economia que os macroeconomistas e economistas do mercado financeiro estão particularmente interessados é o cálculo da taxa de inflação e das taxas de juros esperadas para os próximos períodos. Acertar antecipadamente as expectativas inflacionárias e o valor da taxa de juros SELIC - fixada mensalmente pelo Banco Central do Brasil (BCB) - pode ajudar os agentes econômicos a tomar decisões corretas de investimentos e consumo.

$\mathrm{O} \mathrm{BCB}$, por intermédio do sistema de Metas de Inflação, tem sob sua responsabilidade manter a taxa de inflação sob controle. Este sistema, implantado no Brasil em 1999 fixa a meta de taxa de inflação fazendo com que a taxa de juros SELIC seja o principal instrumento de política monetária para alcançar o objetivo proposto. Por isso a fixação das taxas de juros em cada reunião do Comitê de Política Monetária (COPOM) se apóia na previsão de inflação.

Neste sentido, se o BCB projetar o aumento da taxa de inflação em 1\%, o COPOM deverá aumentar a taxa de juros SELIC acima de 1\% para desacelerar a economia que, de seu ponto de vista, corre o risco de estar superaquecida. Caso a projeção esteja errada, o BCB corre o risco de provocar uma recessão desnecessária ou um salto indesejável na taxa de inflação.

Sabe-se que a meta de inflação para 2005 é de 5,1\%, com um teto máximo de 7,6\%. $\mathrm{Na}$ Ata do COPOM n 110, de julho de 2005, a mediana das expectativas de inflação para o ano de 2005 foi reestimada em 5,66\% e a taxa de crescimento do PIB para 3\%. O IPCA acumulado no ano (janeiro a julho) está em 3,42\%.

A interpretação das Atas do COPOM, após janeiro de 1999, permite afirmar que a metodologia VAR pode ser uma alternativa para se prever a taxa de juros, que por sua vez, pode determinar a taxa de inflação para os períodos subseqüentes.

\footnotetext{
${ }^{11}$ Mestre em Desenvolvimento Econômico pela UFPR. Professor Assistente da Faculdade Pitágoras de Curitiba. Endereço eletrônico: lucianodagostini@yahoo.com.br.

12 Doutor em Economia (IE/UFRJ), Professor do Departamento de Economia da UFPR e pesquisador do CNPq. Endereço eletrônico: joreiro@,ufpr.br. Web site: www.joseluisoreiro.ecn.br.
} 
O sistema VAR permite aos responsáveis pela política monetária estudar os efeitos causais de um choque na taxa de juros sobre a inflação. Assim, a taxa de juros não é determinada ao acaso, mas sim determinada endogenamente com base na avaliação dos valores correntes e futuros de variáveis como produto, moeda, câmbio e preços.

Desse modo, a taxa de juros de curto prazo pode ser estimada consistentemente por um modelo VAR que assume endogeneidade em todas as variáveis inseridas no sistema. Os procedimentos econométricos usados são resumidos nas seguintes etapas ${ }^{13}$ : (i) Logaritimizar as séries; (ii) Efetuar o teste de raiz unitária pelo ADF; (iii) Efetuar os testes de Cointegração JJ; (iv) Escolher a defasagem ótima do VAR pelo critério de Akaike (AIC) e Schwartz (SBC); (v) Conforme o teste Johansen-Juselius (JJ) adota-se o modelo VAR simples ou com correção de erro (VECM); (vi) determinar os coeficientes das equações por MQO; (vii) observar a equação de equilíbrio de longo prazo entre as variáveis, dado pelo VECM e a equação da taxa de juros.

No mais, a grande dificuldade é determinar as variáveis que o BCB utiliza para inserir no modelo VAR. De qualquer forma, o exercício na tentativa de previsão da taxa de juros SELIC usa dados mensais, de janeiro de 1999 a julho de 2005. As variáveis são: preços, juros, produto, câmbio e moeda. Para preços, utilizou-se o IPCA, código 433 do IBGE, por ser a taxa de inflação utilizada pelo BCB para estabelecer a Meta de Inflação anual. Para a taxa básica nominal de juros, utilizou-se a SELIC, código 4189 do BCB. Esta taxa de juros é a taxa pelo qual o BCB tenta controlar a inflação. Para produto utiliza-se o PIB mensal em valores correntes, medida em milhões de reais, código 4380 do BCB. A série de moeda é $\mathrm{M}_{2}$, código 1837 e a série de câmbio nominal é a 3697, ambos do BCB.

De acordo com a equação de previsão da taxa de juros estimada a partir de um modelo VAR (5) com correção de erros explicitada em anexo, os resultados encontrados estão dispostos na tabela 1:

\footnotetext{
13 Para detalhes dos procedimentos metodológicos, ver D’Agostini (2004). Monismo e não-Monismo no Brasil (1994-2004): Uma Abordagem Econométrica por Vetores Auto-Regressivos com Restrição. Tese de Mestrado. Defendida em Nov.2004. Curitiba, UFPR e anexos.
}

30 
Tabela 1. Comparação da Taxa Selic Efetiva com a Taxa Selic Estimada em \% a.a.

\begin{tabular}{lccc}
\hline Mês & Selic Efetiva \% a.a. & Previsão Selic pelo modelo VAR & Elasticidade Juros \\
\hline Jan/05 & 17,93 & - & 0.0149422635447 \\
Fev/05 & 18,47 & 18,20 & 0.0183421456399 \\
mar/05 & 18,97 & 18,81 & 0.0239458042652 \\
Abr/05 & 19,32 & 19,42 & 0.0202736630276 \\
mai/05 & 19,61 & 19,69 & 0.0102073087353 \\
Jun/05 & 19,75 & 19,81 & -0.0147442951648 \\
Jul/05 & 19,75 & 19,49 & $-3.711200463 \mathrm{E}-06$ \\
Ago/05 & 19,75 & 19,70 & -0.0166260004567 \\
Set/05 & $?$ & 19,42 & - \\
\hline
\end{tabular}

Fonte: Banco Central do Brasil e Dados da Pesquisa.

Nesse contexto, existem duas questões importantes para serem analisadas: a precisão de nossas previsões da SELIC e a sinalização que a informação fornecida pela elasticidade juros nos dá quanto a uma provável manutenção na taxa de juros no mês de agosto e uma provável queda para setembro.

Em primeiro lugar, com base na Tabela 1, percebemos que o modelo parece fornecer um bom indicador sobre o comportamento de curto-prazo da taxa de juros porque o valor calculado aproxima-se bastante da taxa de juros fixada pelo BCB. Em segundo lugar, as elasticidades negativas calculadas pelo modelo, nos meses de junho a agosto, sinalizam que o governo já poderia ter reduzido a taxa de juros SELIC há dois meses atrás.

Para o mês de setembro o modelo indica a previsão da SELIC em 19,42\%, pois a elasticidade juros do mês de agosto é -0.0166260004567. Daqui se segue que existe uma grande probabilidade de que na próxima reunião do COPOM, a ser realizado no mês de setembro, o Banco Central reduza a taxa de juros SELIC em 0,25 pontos percentuais, de $19.75 \%$ para $19,50 \%$ ao ano.

Essas assertivas se baseiam no fato de que as previsões do nosso modelo VAR têm acompanhado de perto a evolução da taxa SELIC efetiva. Como o modelo apontou uma taxa de juros de cerca de 19,70\% para agosto de 2005, e dado que o COPOM resolveu manter a taxa de juros inalterada em 19.75\% ao ano na última reunião - provavelmente um reflexo do medo de contaminação da economia pela crise política em Brasília, num contexto em que a Meta de Inflação está controlada - é praticamente certo que o Banco Central irá iniciar o processo de redução da taxa de juros no mês de setembro. 


\section{ANEXO}

A equação de previsão da taxa de juros simulada é:

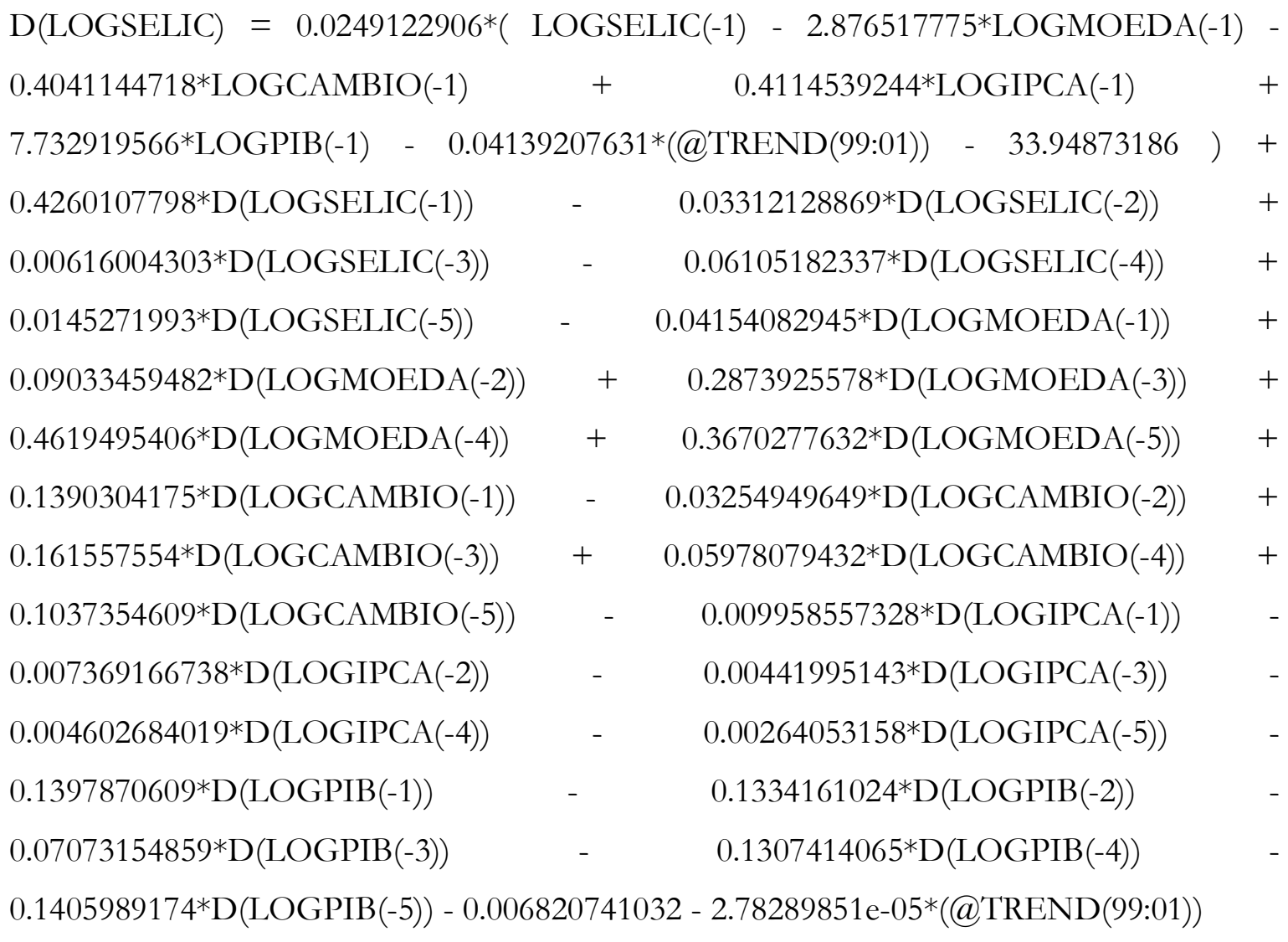

Onde $\mathrm{D}($.$) é a primeira diferença; (-1),(-2) \ldots,(-5)$ são as defasagens das variáveis utilizadas no modelo e; @TREND (.) é o componente de tendência.

Devemos enfatizar que o modelo é do tipo LOG-LOG. Isto faz com que os coeficientes dos parâmetros estimados sejam interpretados como elasticidades da taxa de juros com respeito às variáveis do sistema.

Efetuando as substituições dos valores das variáveis defasadas no sistema, para diversos períodos de tempo, temos o valor das elasticidades dos juros. Estas elasticidades por sua vez determinam, para os períodos $t+1, t+2, \ldots, t+n$, os valores das previsões das taxas de juros subseqüentes.

Por questões probabilísticas do modelo, quanto maior é o tempo de previsão menor é a possibilidade de acerto. Portanto, o modelo VAR serve apenas para previsões de curto prazo. Por isso, restringe-se, na Tabela 1 , o valor esperado da SELIC para três períodos à frente, ou seja, de julho a setembro. Do mesmo modo, mostram-se os valores passados previstos e efetivos da taxa de juros, de modo a contribuir para a robustez do modelo. 